\title{
A BOOK REVIEW: FEMINISM AND/VERSUS FEMINITY OF MODERN WOMEN
}

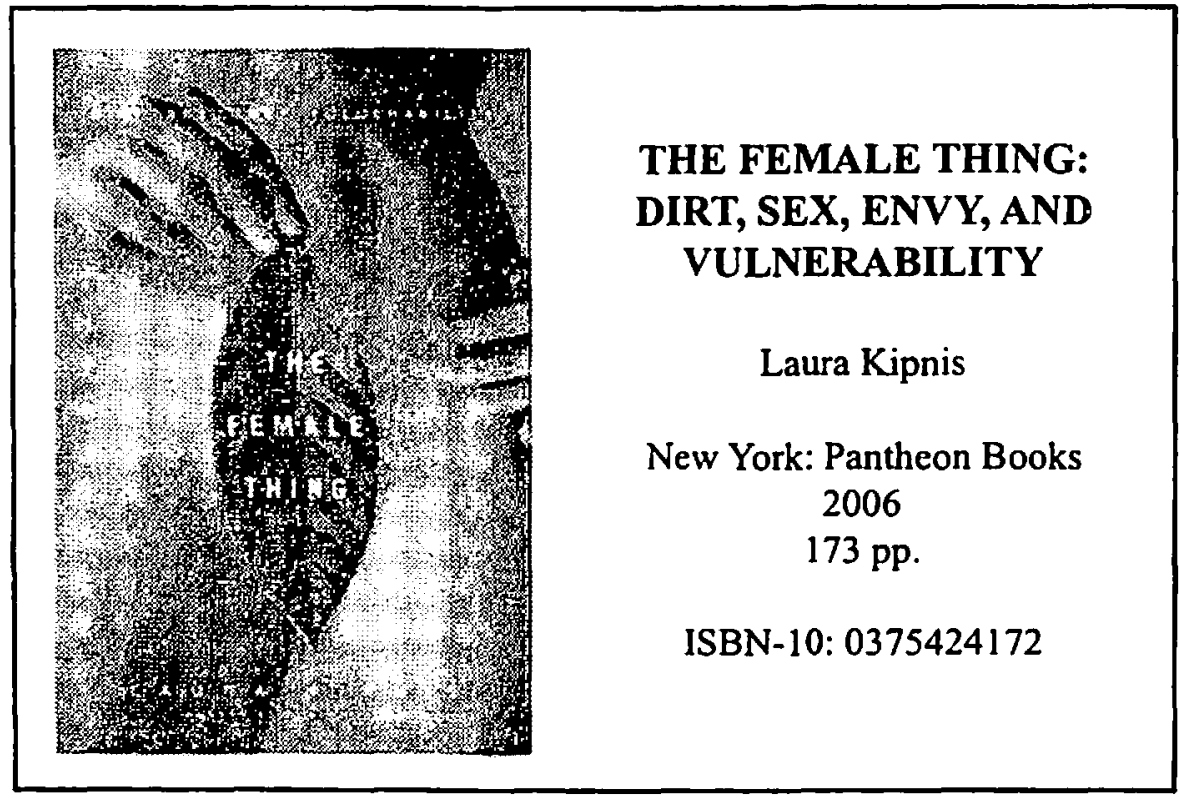

\section{Reviewed by B. Retang Wohangara'}

One important theme attached to pop culture is the politics of representation and sub-cultural identity. The pop singer Madonna and then the Spice Girls are frequently regarded as the representation of modern women offering a different face of feminism ideology. Successfully entering the market competition, Madonna, through her cry of 'material girl', characterizes herself as an independent woman in the still dominating patriarchal world while challenging the burden of

B. Retang Wohangara, S.S., M.Hum. <wohangara@yahoo.com> is a fulltime lecturer of the Faculty of Letters, Soegijapranata Catholic University, Semarang. He is currently working his way to being a doctorate candidate in Indiana Bloomingston, U.S.A. with Ford Foundation. 
morality placed on the shoulders of women. She asks young women to rebel against male-centred traditions and unashamedly exposes her sensuality as a source of power and even domination, or in short celebrating 'being women'. The flag of Girl Power is also waved by the 1990's British female singers, the Spice Girls, who call young girls to "be strong, be brave, be loud and control your own destiny. Believe that your self can do anything you want to do and be confident. We have to be independent, but it does not mean that you don't need a boy" (Swastika 2004: 66).

The phenomena of Madonna and Spice Girls undeniably instigate new ways of redefining feminism and femininity and trigger questions on how modern women, especially the young ones, perceive their existence and sensuality. Some feminists, such as Mandzuik accuses Madonna of blurring the genuine politics of feminism by masking herself as the representative of an independent woman who is willing to "sleep with the enemy" (1997:142). Madonna is playing games, which in fact traps her in subjugation to patriarchy and in the 'commodification' of body to meet consumers' needs. The Spice Girls' Girl Power is also perceived, mainly by the second-wave feminists- as another way of constructing (young) women to be potential targets of capitalistic strategies. The slogan of Girl Power portrays the popular feminism which is caught between the contradictive goals: struggling for girl empowerment and forcing back the standard of patriarchy in defining their sexual identities.

In her book The Female Thing: Dirt. Sex, Envy, and Vulnerability, Laura Kipnis, a professor at Northwestern University best known for her provocative defence of adultery in Against Love: $A$ Polemic, addresses the above contradiction, or better to say ambivalence, by out that when women are talking about gender progress and all impediments to it, they will encounter a female situation bearing inner conflicts among women themselves like "ingrown hairs after a bad bikini wax" (2006: vii). In one hand, feminism has to some extent made female progresses, such as, the crumbling of gender barriers, the eradication of the dominant paradigms of patriarchy, and the increasing dependence of women, but in the other, it also faces the endless quest of women's self improvement of female anatomy, or the inclination to remain chained in many traditionally feminine ways. Kipnis (2006: 6-7) claims that feminism and femininity are incompatible in 
nature, due to the facts that the first wants to eliminate female inadequacy for it is regarded a merely patriarchal myth, the latter centres on the endless underlying sense of female inadequacy. In this light, instead of pointing fingers to the common suspects: men and media, at least not primarily, or even not anymore, of the present female condition, Kipnis (2006) argues, that the culprits are closer to home: the inner women themselves. Women are driving themselves nuts attempting to bring together two entirely opposing ideas: feminism and femininity.

Since women's relation to their bodies is among the many things that does not yield progress, Kipnis aims her book to map female inner life by scrutinizing the four primary regions of female psyche in four discursive essays: Envy, Sex, Dirt, and Vulnerability, of what she calls a provisional topography, meaning it is open to updating. Those four are of special importance since they intimately link to female anatomy which dictates female condition. Each essay explores "the local conflicts and uneven developments and political miscalculations: a series of bulletins on the female predicaments- in one corner of the world, at least" (Kipnis 2006:xii).

\section{ENVY}

After long decades of the women's liberation movement, exist the two competing theories of what women naturally are versus what women can become, or whether women should act like men or more like powerful women. Middle and upper class white women in the consumer world today, Kipnis (2006:6) writes, are "left straddling two rather incompatible positions: feminism ("Don't call me honey, dickhead"), and femininity ("I just found the world's best push-up bra!"). While the struggle for women empowerment is still in the air, the feminine-industrial complex of modem life, indeed conditions women to admit a kind of ontological flaws resulting to the magnitude of their anxiety about lacking something. The sense of elusive "missing something" has been the dynamic drives of women's culture, and consequently makes women the world's most dedicated consumers, or as Kipnis puts it, "the female and consumer culture: the world's ultimate co-dependent couple" (2006:11). This feeling of incompleteness sounds back Sigmund Freud's debatable phrase of 'penis envy', referring to the female sense of inadequacy toward male. 
Husbands and babies have been the traditional mechanism for moderating any nagging sense of female completion, but in this time, in addition to the "if only men could be different-more like women" frustrating expectation, education, career, the ideal thinness, and the war on cellulite are among others the modern answers. Yet women, the career ones, want more... and more... due to their ever-misșing something. For Kipnis, talking about the present female condition will bring us to Nietzsche's term, resentment, which is "a way of projecting the pain and frustration that accompanies feelings if inferiority onto some external scapegoat. Men for instance." (2006:36). She makes a hilarious parody of the cult of femininity and challenges the tendency to focus all female disappointments on men.

\section{SEX}

The essay on Sex presents relatively extensive discussions on female sexuality: vagina, clitoris and the pleasure relating to the anatomical organs, taken from historical, psychological, medical, and anthropological point of views. For Kipnis, female pleasure has been "one of human history's ongoing snuggles," (2006:44) and has been an important battlefield for sexual equality. Going back as far as the pre- eighteen century, the sexual desire of female desire was regarded equivalent to that of male, and it was believed that "the female body had all the same organ as male, just located on the inside rather than the outside... The vagina was an inverted penis, the ovaries were female testicles, the womb was a scrotum" (2006:68). Then in the Victorian era, there was existing doubt that women had sexual desire at all. In the present time, another turn occurred; that female desire is stated completely different from male.

The advent of Pill in 1960 indeed catalyzed sexual revolution in Western world. From that time onward, female sexuality has perceived a strategic terrain to attain gender equality: the rights to control female's own body and sexual pleasures without being exclusively tied by the traditionally-hold pro-creation purposes. In the spirit of sexual emancipation, the accounts of female sexual experience reveal that there is a highly percentage sexual-gap between men and women (the sexual dissatisfaction of women is certainly not a new finding), and the sexual 
stumbling block for women has always been said the "relative inefficiency of penetration as a means of producing female orgasm" (2006:49). Diagnoses, treatments, therapies, battery powered and electrical models of vibrator and phallus are invented to solve the fundamental female dilemma. Sexual narratives on vaginal and clitoral orgasm have developed, yet anxiety on female side remains. Kipnis wonders if the women's sexual anxiety is due to "whether because not reaching orgasm during penetration is sexually disappointing or because men are having more of them, and women are getting cheated" (2006:55). Furthermore, sexual revolution gets nowhere if women's maternal instinct is sacrificed for the obsession to be like or more than men.

\section{DIRT}

Historically and culturally, accusations of dirtiness have been put on women's parts, and various forms of rituals are carried out to purify the "contaminating" women (Kipnis 2006:84). The belief that women are somehow polluting appears when menstruating women are regarded dangerous to men's health and crops and livestock as well. Throughout generations, men have conducted decontamination rituals to protect themselves from female poisons. Menstruating women are not allowed, to mention some, to prepare or serve food, to touch hunting bows, to enter religious shrines. After the long association of dirtiness to this sex, women seem to be neurotic about cleanliness. Cleanliness for women dealing with either housework or their body is a representation of their selves and portrays their own self-worth, and "despite the numerous transformations in the female role, this self-identification of women with cleaning has so psychologically staying power" (Kipnis 2006:101). It is as if, as Kipnis quotes Louise Rafkin, the writer of Other People's Dirt (1999), "Cleaning help me [women] deal with the feelings [of dirtiness] in my body". (2006:102).

The association of home-and-body cleanliness with virtue traps women and men in a battle field, especially the housework, in contemporary gender relations. Domestic work is not exclusively the female's province anymore since male is said to willing to do more housework than in the past. 
However, there is a kind of "neurological differences" (Kipnis 2006:95) between men and women to account for women's inclination to care more about cleanness. For women, it is true that men generally manage to have a share in domestic chores, yet men deal with them carelessly. Men do not sufficiently care about dirt; they do not notice what needs doing, or what household items need replacing. Men are unbelievably indifferent about all. Kipnis concludes that the root of women's ever-increasing resentment of men is located on their own self-denial and self-deception. Their over expectations are attributed more to a lack of personal fulfilment than to the inadequacies of men.

\section{VULNERABILITY}

In this last section of her book, Kipnis refers the sub-title Vulnerability mostly to V-word, vagina, the women's sexual organ making them vulnerable for being inherently rape-able. For feminist, like Susan Brownmiller, rape is a "domination tactic deployed against women as a class, keeping the female population reflexively submissive... Rape is one of the culture's ways of feminizing women" (cited in Kipnis 2006:125, 126). Since men have the anatomical ability to accomplish it, they are thus able to exploit female fear for political and social benefits.

Present women's living with the constant awareness of rape inevitably shapes their female behaviour and psychology. However, for Kipnis, the threat of rape and the physical harm from men are made bigger issues than the actual ones and therefore reinforce conventional feminine fear and vulnerability. Most violent crimes are actually committed against men, and rape and sexual assault against women are actually low, yet women fear crime far more than men (KIPNIS 2006:131). She blames this unnecessary fear on alarmist sexual paranoia propagated by radical 70 s feminists such as Andrea Dworkin. "It's a genre of feminism", Kipnis writes, "dedicated to revivifying an utterly traditional femininity: wounded-bird femininity" (2006:147).

Although Kipnis's The Female Thing: Dirt, Sex, Envy, and Vulnerability may leave us frown of whether or not she falls into superficial analyses or hasty generalizations, the book may be read as a clever, comic, 
ironic way to rouse the consciousness of the inner conflicts and inconsistencies characterizing the modern female condition. The book may be leafed through as an audit of feminism's progress, which is hopefully recognisable to every woman.

Kiplin does not offer, neither does mean, to offer advices to the ambivalence between feminism and femininity of modern female situation, as she lets her readership to figure them out by stating "a full accounting of the female situation at the moment would need to start roughly here" (2006:163) at the end of the book. In this consumer-driven culture, women progress is challenged by the 'something is missing' notion and it is indeed the huge task of women to (re)construct their personalities and lifestyles without moaning too much about men. In her funny and fierce presentation, she reminds women to look at themselves as worst enemies in the battle for equal rights.

\section{BIBLIOGRAPHY}

Kipnis, Laura. The Female Thing: Dirt, Sex, Envy, and Vulnerability. New York: Pantheon Books, 2006.

Mandzuik, Roseann. "Feminists Politics and Postmodern Seductions. In Postfeminism, Feminism, Cultural Theory and Cultural Forms. Edited by Ann Brooks. Routledge: London, 1997.

Swastika, Alia. "Apakah Saya Feminist? Mengeja Girl Power dalam Majalah Gadis". In Jurnal Perempuan, Vol. 34. Yayasan Jumal Perempuan: Jakarta, 2004. 